\title{
Why we need interprofessional education to improve the delivery of safe and effective care
}

Scott Reeves $(\mathrm{a})$

Reeves S. Porque precisamos da educação interprofissional para um cuidado efetivo e seguro. Interface (Botucatu). 2016; 20(56):185-96.

Interprofessional education (IPE) is an activity that involves two or more professions who learn interactively together to improve collaboration and the quality of care. Research has continually revealed that health and social care professionals encounter a range of problems with interprofessional coordination and collaboration which impact on the quality and safety of care. This empirical work resulted in policymakers across health care education and practice to invest in IPE to help resolve this collaborative failures. It is anticipated that IPE will provide health and social care professionals with the abilities required to work together effectively in providing safe high quality care to patients. Through a discussion of a range of key professional, educational and organization issues related to IPE, this paper argues that this form of education is an important strategy to improve the delivery of safe and effective care

Keywords: Interprofessional education. Collaborative learning. Interprofessional collaboration. Teamwork. Patient safety.

\begin{abstract}
A educação interprofissional (EIP) é uma atividade que envolve dois ou mais profissionais que aprendem juntos de modo interativo para melhorar a colaboração e qualidade da atenção à saúde. Pesquisas vêm revelando continuamente que profissionais de saúde e serviço social enfrentam uma série de problemas na coordenação e colaboração interprofissional que impactam na qualidade e segurança da atenção. Estes estudos empíricos levaram formuladores de políticas de atenção e educação na saúde a investir em EIP para ajudar a enfrentar tais dificuldades colaborativas. Espera-se que a EIP possibilite a profissionais de saúde e serviço social as habilidades necessárias para trabalhar efetivamente juntos para garantir uma atenção de alta qualidade e com segurança para os pacientes. Ao discutir uma série de problemas profissionais, educacionais e organizacionais relacionados à EIP, o presente trabalho defende que esta forma de educação é uma estratégia importante para garantir uma atenção à saúde segura e eficaz.
\end{abstract}

Palavras-chave: Educação interprofissional. Aprendizado colaborativo. Colaboração interprofissional. Trabalho em equipe. Segurança do paciente.

\footnotetext{
(a) Kingston University \& St George's, University of London, Centre for Health and Social Care Research. St George's Hospital, London, London SW17 ORE, United Kingdom.s.reeves@ sgul.kingston.ac.uk
} 


\section{Introduction}

Interprofessional education (IPE) provides learners with opportunities to learn together with other professions to develop these attributes and skills, required for working in a collaborative manner. This paper discusses a range of pertinent professional, educational and organization issues related to IPE. Specifically, this paper describes the emergence of IPE, outlines key learning and teaching approaches used to deliver effective IPE, explores the complex organizational factors linked to its implementation and reports on the growing evidence base for IPE. The paper goes on to discuss these various elements and also outlines implications for the future development of IPE.

\section{Emergence of IPE}

Globally, for over three decades, health policy makers have identified the key role of IPE in improving health care systems and outcomes ${ }^{1,2}$, but during the past ten years, it has particularly been at the forefront of much research, policy, and regulatory activity on an international level ${ }^{3}$. IPE is defined as occasions, "two or more professions learn with, from and about each other to improve collaboration and the quality of care" ${ }^{4}($ p. 1). As such, this definition encompasses both prequalification and post qualification learners.

The need for IPE stems directly from the complexity and multifaceted nature of patients' health and social care needs which requires effective coordination of services ${ }^{3}$. It also stems from research demonstrating that effective collaboration amongst multiple health care providers is essential for the provision of effective and comprehensive care ${ }^{5}$. Indeed, problems with communication and collaboration amongst different health and social care professionals continue to be a concern as they can comprise the delivery of patient care ${ }^{6,7}$. Studies in North America have, for example, revealed how damaging the impact of communication failures can be for patients resulting in undermining patient safety and causing serious injury or even death ${ }^{8,9}$.

The collective view of the literature cited above is that health and social professions need education and training to provide them with the attitudes, knowledge and skills needed to work effectively together to deliver safe, high quality patient care. Policy documents have supported the need for IPE to help to improve collaborative competencies ${ }^{10,11}$. Recently, the World Health Organization ${ }^{2}$ reenforced its commitment to IPE highlighting the importance of this form of education to develop the skills needed to be ready for collaborative practice and safe patient care. Importantly, this document outlines the significant need of IPE and collaborative practice to help improve fragmented and struggling health systems throughout the world - in both developed and developing countries.

These IPE policy documents are affecting changes at the educational, professional, and organizational levels, resulting in the incorporation of IPE into health and social care education programs, regulatory bodies and organizational policies. For example, IPE courses, programs, and centers have been created in higher education institutions in countries such as the US, Canada, UK and Australia ${ }^{5,7}$. In these instances, health and social faculties are working together to provide IPE opportunities for their students. For example, in a study that compared the delivery a patient safety course from both a uniprofessionally and interprofessionally perspective found that while all students increased their knowledge, those who participated in the interprofessional course gained added value from these interactions and felt better able to work within the interprofessional team ${ }^{12}$.

Many health and social care organizations are supporting IPE initiatives. For instance, Barr et al. ${ }^{5}$ report on programs occurring in the UK and US whereby primary care practices and medical centers have made a commitment to support health care improvements through initiatives that involve elements of IPE. This support has also been echoed by different universities, professional associations and health care institutions, who also recognize the need to provide IPE for their learners. 


\section{Key educational and learning methods}

There has been some debate on when is the most effective time to implement IPE within educational and clinical organizations. Research indicating that students entering their first year of a pre-qualification program already have an established and consistent set of stereotypes about other health and social care professional groups has generated the argument that IPE delivered at this time may play an important role in diminishing the negative effects of professional socialisation, such as hostile stereotyping 5 . In contrast, others have suggested that post-qualification IPE is more effective because participants have a firmer understanding of their own professional identity and role. In a survey of students from eight professional groups, it was found that the strength of professional identity in all professional groups was high on entry to university but declined significantly over time for some professions. Students' readiness for IPE was also high at entry but declined significantly over time for all groups except nursing ${ }^{13}$. The results from this study and others ${ }^{14,15}$ support the argument for early IPE given students' readiness for IPE and the existence of professional identities.

It has also been suggested that IPE should form a part of an individual's ongoing professional development, starting in their pre-qualification programs and continuing throughout their careers ${ }^{16}$. Given that the objectives and nature of an IPE initiative will differ depending on the stage of learning, this approach seems appropriate. IPE could initially be used to prepare students for collaborative practice, while this type of education at a later stage could reinforce early learning experiences and further support collaborative practice.

The definition of IPE outlined above stresses the need for explicit interprofessional interaction between participants, as it is argued that this interactivity promotes the development of the competencies required for effective collaboration ${ }^{5}$. Learning methods that enable interactivity are therefore a key feature of IPE. There are a number of different types of interactive learning methods used:

- Seminar-based learning

- Observation-based (shadowing) learning

- Problem-based learning

- Simulation-based learning

- Practice-based clinical placement learning

- E-learning (e.g. on-line discussions)

- Blended learning (combining e-learning with other traditional methods)

The literature contains numerous examples of these five learning activities within IPE initiatives. For example, Freeth et al. ${ }^{17}$ report on a one-day simulation-based course for obstetricians, obstetric anesthetists and midwives to enable improved interprofessional working in obstetric care. The focus of the course is on nontechnical aspects of care and their influence on patient safety. The course involved an initial orientation to the environment, simulation scenarios, and facilitated debriefings.

Combining different interactive learning methods in an IPE initiative can make the experience more stimulating, and interesting and contribute to a more profound level of learning. For instance, one IPE program, which aimed to develop interprofessional patient-centred collaborative skills of students from medicine, dental hygiene, dentistry, nursing and pharmacy, involved an orientation workshop, ongoing educational sessions and an 8-week clinical placement as an interprofessional student team ${ }^{18}$.

The particular learning methods used will depend on the objectives of the IPE initiative, the participants, and the resources available. Students might have more or less familiarity and experience with particular learning methods, such as online learning or simulation, and this variation can be a challenge in an IPE program. 
Opportunities for informal learning - when learners meet socially and discuss aspects of their formal education - are a useful approach for IPE. Informal learning can be helpful in allowing individuals to exchange ideas and obtain guidance from their peers, work colleagues or managers. Informal learning activities can be explicitly built into an interprofessional program. For example, it can be used to provide opportunities to share time during breaks to informally discuss educational experiences. Informal learning can also occur as an 'unplanned' outcome of an interprofessional initiative. In an evaluation of a community-based module ${ }^{19}$, it was found that medical, nursing, and dental students used bars and cafes after their formal learning sessions to informally discuss and reflect upon their IPE. For these students, this type of learning was felt to be a valuable part of their shared experiences on this module.

There are variations in formal interprofessional clinical placement learning opportunities available and informal learning opportunities in the clinical context are influenced by individual professionals and organizational cultures as well as by students' confidence levels ${ }^{20}$. Such informal learning opportunities and the mentorship available, play large roles on students' learning and development.

Combining learning activities designed to promote collaborative outcomes with those designed to promote more profession-specific outcomes can be problematic. Learners may experience uncertainty regarding the overall aim of the IPE. This issue emerged during work on an interprofessional placement for medical, nursing, occupational therapy and physiotherapy students ${ }^{21}$. In order to provide students a holistic insight into a clinical environment, they were offered both collaborative interactive learning activities such as team problem-solving and profession-specific activities such as drug administration - a task that the nursing students exclusively undertook. For the students on this placement, the inclusion of both collaborative and profession-specific learning activities produced tension as it was found difficult to actively participate in both types of activity. After feeding this finding back to the group responsible for developing the placement, it was agreed to review this part of the placement in an attempt to reduce this tension.

Elective or voluntary IPE can give the message that this type of learning occupies a "low status" in relation to other forms of profession-specific learning, which may in turn reduce the learner's commitment to IPE ${ }^{20}$. In addition, if this form of education is not assessed in a way that gives it equal weight with profession-specific education, its status can again be questioned. Eliciting public support from professional leaders and recruiting high-quality educators may help improve the status of IPE. Making attendance compulsory and developing flexible scheduling can prevent logistical challenges from becoming a barrier to effective IPE. Continuing education credits may also provide the needed status, and therefore incentive, to encourage participation of post-qualification practitioners ${ }^{20}$. Nevertheless, for many practitioners, IPE is undertaken on a voluntary basis, and thus incentive is related to their own professional development and/or a wish to enhance the coordination and delivery of patient/client care.

\section{Facilitating IPE}

Facilitating IPE can be challenging, and requires skill, experience and preparation to deal with the various responsibilities and demands involved. It is ideal to train facilitators from the diverse faculty involved, and the number of facilitators required can be large, particularly in a pre-qualification context, depending on the number of students. There are a range of attributes required for this type of work, including:

- Experience of interprofessional work (to draw upon when facilitating)

- In-depth understanding of interactive learning methods

- Knowledge of group dynamics

- Confidence in working with interprofessional groups

- Flexibility (to creatively use professional differences within groups) 
Similar to other small-group education, facilitators need to focus on team formation and team maintenance, to create a non-threatening environment, and enable all leaners to participate equally. However these aims are challenging in an interprofessional context given the history of social and economic inequalities, and friction, that exist between the members of the health and social care professions. Friedson' $\mathrm{s}^{21}$ work provides an understanding to the roots of these imbalances. He argued that all occupational groups actively engage in a process of professionalisation through engagement in a 'closure' project. The aim of this project was straightforward - to secure and then protect exclusive ownership of specific areas of knowledge and expertise in order to effectively secure economic reward and status enhancement. As medicine was the first health occupation to successfully engage in a professionalisation project they claimed the most highly prestigious areas of clinical work - the ability to diagnose and prescribe - which ensured their dominant position over the other health and social care professions ${ }^{22}$. Exploring this theme, Pecukonis et al. ${ }^{23}$ argue that different professional cultures shape differing definitions of health, wellness and treatment success, as well as power differences. They also argue that IPE is limited by profession-centrism and this must be addressed through a curriculum that promotes interprofessional cultural competence.

Given the challenges related to facilitating IPE, faculty development is crucial for educators. For most educators, teaching students how to learn about, from and with each other is a new and challenging experience. Similarly to students, staff and faculty may also struggle with interprofessional and uni-professional issues; for example the increasing emphasis on IPE and can challenge professional identities. Faculty development may reduce feelings of isolation, develop a more collaborative approach to facilitation, as well as provide opportunities for faculty to share knowledge, experiences and ideas ${ }^{24}$.

There are a growing number of faculty development programs. In general, they focus on offering a similar range of preparatory activities, such as understanding the roles and responsibilities of the different professions, exploring issues of professionalism, and planning learning strategies for interprofessional groups. There is also a need for IPE faculty development programs to enable individuals to promote change at the individual and organizational level, and thus should also target diverse stakeholders and address leadership and organizational change ${ }^{25}$. To ensure that faculty maintain their knowledge of interprofessional facilitation, they need ongoing faculty development opportunities. Often, it is useful to consider team-teaching with more experienced colleagues to help develop the range of necessary skills, knowledge and confidence that are vital for interprofessional facilitation. Regular opportunities for discussion and reflection can be a useful type of support for facilitators of IPE ${ }^{26}$. Where formal training cannot be obtained, it is advisable to seek informal input from a colleague more experienced in this type of work. For IPE to be successfully embedded in curricula and training packages, the early experiences of staff must be positive. This will ensure continued involvement and a willingness to further develop the curriculum based on student feedback.

\section{Organizational factors affecting IPE}

Organizational support is crucial to a successful IPE program, and consists of various components. It is critical to have leadership with interest, knowledge, and experience to advance the IPE agenda, and an organization and faculty supportive of IPE is needed to instill within students a positive attitude to this type of learning ${ }^{27}$. Institutional policies and managerial commitment are also crucial given the resources required to develop and implement IPE. This form of leadership and 'buy-in' is needed from all the participating organizations or departments within an organization.

The particular type of organizational support required is often dependent on the stage of education. Planning and implementing pre-qualification IPE is challenging given the high number of organizational barriers, such as large numbers of students, professional accreditation requirements, and inflexible curricula, which exist. Most pre-qualification programs for medicine and nursing have 
cohorts of between 100-200 students. In contrast, occupational therapy and physiotherapy programs typically have smaller cohorts of between 20-60 students. This creates logistical difficulties over finding a suitable location for this type of education. In addition, differences in course timing for these student cohorts can create further problems around finding a suitable slot to deliver IPE ${ }^{28}$. Obtaining approval from each of the participating profession's regulatory bodies often adds additional complications, as well as agreeing on issues of accountability.

While post-qualification IPE can be less problematic to plan because of the fewer institutional barriers, institutional support is required to provide health care providers with the time and resources to attend such education programs. Therefore support is required to foster a positive attitude to this type of education. Furthermore, organizational support is critical if any knowledge gains are going to be successfully translated into interprofessional practice changes.

In addition, the issue of finance needs careful consideration during the planning of any interprofessional initiative. As the cost of this form of education tends to span a number of different professional or departmental budgets ${ }^{28}$, agreement over financial arrangements can often be a main hurdle for IPE.

Developing interprofessional curricula is a complex process, and may involve health care workers and educators from different faculties, work settings and locations, which complicates IPE planning and implementation. Indeed, involving faculty from the different programs involved in the initiative is crucial, and all programs involved should have a sense of ownership. This can be challenging with smaller faculty. Equal representation ensures that no one group can dominate the planning process and skew the initiative in any one direction ${ }^{29}$.

As developing IPE can take considerable time and energy, group members need to have dedication and enthusiasm. However, when IPE programs are dependent on the input of a few key enthusiasts, it's long term sustainability can be threatened when these individuals move to other organizations. In an evaluation of an interprofessional clinical placement for nursing, medical, occupational therapy and physiotherapy students, it was found that the sustained enthusiasm of steering group members was critical to overcoming various practical issues such as joint validation and the establishment of a pilot placement. Without this type of group effort, IPE cannot be developed and implemented ${ }^{28}$.

The election of an IPE project leader is important to coordinate the group activities and ensure progress is achieved. Organizers need to arrange regular meetings and consider all perspectives and also require interprofessional skills ${ }^{28}$. Group members need to share their aims and assumptions about the initiative to ensure that all members are working towards a common goal. Where differences are identified, these need to be discussed and resolved. Regular planning meetings allow group members to update one another and jointly problem-solve any difficulties they encounter in the planning process.

Sustaining IPE can be equally complex and requires good communication among participants, enthusiasm for the work being done, and a shared vision and understanding of the benefits of introducing a new curriculum. Organizations need to constantly evaluate, revise and discuss IPE in the organization and to remind all members about the general goals of IPE, which is improved interprofessional practice ${ }^{27}$.

\section{The evidence}

During the past decade, a number of IPE systematic reviews have been conducted to examine and summarize the evidence of the field ${ }^{29-31}$. The reviews used different criteria for the studies to be included, and thus while there was overlap, each examined a different group of studies. With colleagues, a few years ago I conducted a synthesis of the IPE systematic reviews to provide an overall understanding of the evidence base ${ }^{32}$. The synthesis included six systematic reviews that were identified following an electronic search for published and unpublished IPE reviews. The following section reports on this synthesis and the findings. 
The six reviews included in the synthesis report on the effects of over 200 IPE studies spanning 30 years. These six reviews report on studies which differ in methodological quality, and report a range of outcomes associated with IPE, yet all reviews share a similar definition of IPE ('two or more professions learning with, from and about each other to improve collaboration and the quality of care'), five were undertaken by similar review teams, and five share similar (methodologically inclusive) approaches to their inclusion criteria ${ }^{32}$.

Five of the reviews employ a similar approach to recording IPE outcomes. Originally developed by Kirkpatrick as a four-point typology distinguishing four levels of outcomes (learners' reactions, acquisition of knowledge/skills/attitudes, changes in behaviour, changes in organizational practice), which Barr et al. ${ }^{5}$ modified the framework to a six-point typology:

- Level 1: reaction (learners' views on the learning experience and its interprofessional nature)

- Level 2a: modification of attitudes/perceptions (changes in reciprocal attitudes or perceptions between participant groups)

- Level 2b: acquisition of knowledge/skills (gains of knowledge and skills linked to interprofessional collaboration)

- Level 3: behavioural change (individuals' transfer of interprofessional learning to their practice setting and their changed professional practice)

- Level 4a: change in organizational practice (wider changes in the organization and delivery of care)

- Level 4b: benefits to patients/clients (improvements in health or well being of patients/clients)

The synthesis revealed that IPE was delivered in a variety of acute, primary and community care settings and addressed a range of different clinical conditions (e.g. asthma, arthritis) or acute conditions (e.g. cardiac care). While different combinations of professional groups participated in the IPE programs, medicine and nursing were the core participants. IPE was generally delivered as a voluntary (i.e. elective) learning experience to participants and few programs included any form of formal academic accreditation. The duration of programs varied, ranging from a few hour sessions to programs delivered over a period of months, yet most programs lasted between one and five days. Programs were more commonly delivered to post-qualification learners (typically physicians and nurses) in their workplaces, although IPE was increasingly being delivered to pre-qualification learners as a classroom or sometimes as a practice-based activity. While IPE programs used a variety of different combinations of interactive learning methods, seminar-based discussions, group problemsolving and/or role play activities were the most common employed.

Quality improvement principles were often drawn upon within post-qualification IPE programs. In general IPE programs employed formative assessments of learning, typically using assessment techniques in the form of individual written assignments and/or joint/team presentations which provided a collective account of learners' interprofessional experiences. Most programs drew, implicitly, upon the adult learning principles developed by authors such as Knowles, Schon and Kolb ${ }^{32 .}$

The synthesis revealed that the majority of studies provided little discussion of methodological limitations associated with their research. As a result, it was difficult to understand the nature of their biases which in turn undermined the quality of research. In addition, a number of studies only offered limited or partial descriptions of their IPE programs, which makes it difficult to detect whether reported changes are actually attributable to the program delivered.

Most studies paid little or no attention to sampling techniques in their work or issues relating to study attrition. Across the studies, there was a propensity to report the short-term impacts associated with IPE in relation to learner changes of attitude and knowledge. As a result there is only a limited idea of the longer term impact of this type of education, particularly on organizational change and patient care or the educational processes that occur during the delivery of a program. 
There was a widespread use of non-validated instruments to detect impact of IPE on learner and/ or patient satisfaction. While the use of such tools can provide helpful data for local quality assurance issues, they limit the quality of the research as it is difficult to assess their validity or credibility.

Measures to detect changes in individual behaviour were particularly poor, often relying on simple selfreported descriptive accounts of this form of change. Most change recorded in the studies was change that the learners reported themselves. This type of evidence is not regarded as robust, as it does not necessarily detect actual change, it can only report on a person's perception of change. The two do not always concur. Most studies were undertaken in single site studies, in isolation from other studies, limiting the generalisability of research.

Despite a number of weaknesses in the quality of evidence offered by the reviews, there were some encouraging quality issues. Most notably, there was a fairly common use of quasi-experimental research designs (e.g. before-and-after studies; before-during-and-after studies) which can provide some indication of change associated with the delivery of IPE; most studies did gather two or more forms of data (typically survey and interviews); and there is a growing use of longitudinal studies to begin establishing the longer-term impact of IPE on organizations and patient care ${ }^{32}$.

The synthesis found that most studies report that IPE can result in positive learner reactions, where the learner 'enjoyed' their interprofessional experiences. Such studies also report positive changes in learner perceptions/attitudes in relation to changes in views of other professional groups, changes in views of interprofessional collaboration and/or changes in views of the value attached to working on a collaborative basis with other professions. In addition, these types of studies report positive changes in learner knowledge and skills of interprofessional collaboration, usually related to an enhanced understanding of roles and responsibilities of other professional groups, improved knowledge of the nature of interprofessional collaboration and/or the development of collaboration/ communication skills.

Few studies report outcomes related to individual behaviour, usually reported as practitioners' working in a more collaborative manner with their colleagues from other professional groups. Of those studies which do provide evidence at this level, positive change in individual practitioners' interactions is usually cited. A number of studies report positive changes to organizational practice resulting from the delivery of IPE. Research used to report this type of outcome usually focus on changes to interprofessional referral practices/working patterns or improved documentation (i.e. guidelines, protocols, use of shared records) related to the organization of care. A smaller amount of studies report changes to the delivery of care to patients/clients. These studies typically reported positive changes to clinical outcomes (e.g. infection rates, clinical error rates), patient satisfaction scores and/or length of patient stay.

In general pre-qualification IPE studies report outcomes in relation to changes to attitudes, beliefs, knowledge and collaborative skills. While post-qualification studies report a similar range of learneroriented changes, they also report changes to organization practice and patient care. As the synthesis indicated, the evidence for the effects of IPE rests upon a variety of different programs (in terms of duration, professional participation, etc), methodologies and methods (from experimental research studies to mixed methods and qualitative studies) of variable quality, as well as a range of outcomes (e.g. reports of learner satisfaction to changes in the delivery of care). While the quality of evidence for IPE is currently limited, it is improving as higher quality studies continue to be published ${ }^{32}$. 


\section{Discussion}

As detailed above, accumulating evidence of problems with interprofessional coordination and collaboration amongst different health and social care providers, and the resulting impact on the quality of health care, has stimulated decision makers in education, healthcare, policy, and research, to invest in IPE. It is anticipated that IPE will provide health care providers with the skills and knowledge required to work effectively with other health care providers in the health care system. As a result, IPE initiatives for pre and post-qualification learners are being developed and implemented across the globe.

Research evidence for over three decades have provided useful insight into IPE, as discussed above. Through these studies we have an understanding about the value of IPE at both pre- and postqualification learning stages. For example, students can benefit from a pre-qualification initiative about the roles of different health care professionals in relation to a particular clinical area being studied in a classroom and/or placement context, while a post-qualification initiative can address communication issues with other health professionals with whom they work, and support changes in practice. We also have knowledge about the different types of interactive learning methods that can be used in IPE. The opportunity for interactivity is an essential element of IPE, but the particular methods used will depend on the objectives and resources.

Organizational support is critical to address the extensive logistical and resource issues for IPE, to support faculty development, and to develop a culture that endorses IPE, and in the context of health care settings, facilitates knowledge translation. Leadership from schools, associations, and organizations, is thus essential to encourage and support students and practitioners fully engaging in IPE programs.

Future investment in IPE must be based on rigorous evidence though, concerning the outcomes achieved, and this evidence is gradually accumulating. As the synthesis of IPE reviews revealed, this type of education can have positive outcomes in relation to participants' reactions, attitudes, knowledge/skills, behaviours, and practice, as well as patient benefits ${ }^{30}$. Nevertheless, as noted in this paper, there are methodological limitations to these studies. With the expanding number of studies in this area, and the increasing focus on the methodological quality of such studies, it is hopeful that the evidence of this field will be increasingly more robust.

Research has helped to indicate the role of IPE in improving interprofessional collaboration and enhancing the quality of care delivered to patients. Health and social care education schools and associations across the world have emphasized the importance of their students and practitioners being effective collaborators and communicators, and are using IPE as a key strategy to the development of such abilities. As the evidence for IPE continues to evolve, we will develop greater knowledge of how it can most effectively be planned and implemented, and its relationship to developing collaborative competences that can positively affect the delivery of patient care and health outcomes. 


\section{References}

1. World Health Organization. Continuing education of health personnel. Copenhagen: WHO Regional Office for Europe; 1976.

2. World Health Organization. Framework for action on interprofessional education \& collaborative practice. Geneva: WHO; 2010.

3. Institute of Medicine. Interprofessional education for collaboration: learning how to improve health from interprofessional models across the continuum of education to practice. Washington (DC): The National Academies; 2013.

4. Barr H, Hammick M, Freeth D, Koppel I, Reeves S. Evaluating interprofessional education: a UK review for health and social care. London: BERA/CAIPE; 2000.

5. Barr H, Koppel I, Reeves S, Hammick M, and Freeth D. Effective interprofessional education: argument, assumption and evidence. Oxford: Blackwell; 2005.

6. Kvarnstrom S. Difficulties in collaboration: a critical incident study of interprofessional healthcare teamwork. J Interprof Care. 2008; 22(2):191-203.

7. Reeves S, Lewin S, Espin S, Zwarenstein M. Interprofessional teamwork for health and social care. Oxford: Wiley-Blackwell; 2010.

8. Williams RG, Silverman R, Schwind C, Fortune JB, Sutyak J, Horvath KD, et al. Surgeon information transfer and communication: factors affecting quality and efficiency of inpatient care. Ann Surgery. 2007; 245(2):159-69.

9. Brock D, Abu-Rish E, Chiu CR, Hammer D, Wilson S, Vorvick L, et al. Interprofessional education in team communication: working together to improve patient safety. BMJ Qual Safety. 2013; 22(5):414-23.

10. Interprofessional Education Collaborative Expert Panel. Core competencies for interprofessional collaborative practice: Report of an expert panel. Washington (DC): Interprofessional Education Collaborative; 2011.

11. The Interprofessional Curriculum Renewal Consortium. Curriculum Renewal for Interprofessional Education in Health. Sydney: Centre for Research in Learning and Change, University of Technology; 2013.

12. Anderson E, Thorpe L, Heney D, Petersen S. Medical students benefit from learning about patient safety in an interprofessional team. Med Educ. 2009; 43(6):542-52.

13. Coster S, Norman I, Murrells T, Kitchen S, Meerabeau E, Sooboodoo E, et al. Interprofessional attitudes amongst undergraduate students in the health professions: a longitudinal questionnaire survey. International J Nurs Stud. 2008; 45(11):1667-81.

14. Curran V, Sharpe D, Flynn K, Button P. A longitudinal study of the effect of an interprofessional education curriculum on student satisfaction and attitudes towards interprofessional teamwork and education. J Interprof Care. 2010, 24(1):41-52.

15. Costa MV, Vilar MJ, Azevedo GD, Reeves S. Interprofessional education as an approach for reforming health professions education in Brazil: emerging findings. J Interprof Care. 2014; 28(4):379-80.

16. Reeves S. An overview of continuing interprofessional education. J Cont Educ Health Prof. 2009; 29(3):142-6.

17. Freeth D, Ayida G, Berridge EJ, Mackintosh N, Norris B, Sadler C, et al. Multidisciplinary obstetric simulated emergency scenarios: promoting patient safety in obstetrics with teamwork-focused interprofessional simulations. J Cont Educ Health Prof. 2009; 29(2):98-104.

18. Mann K, Mcfetridge-Durdle J, Martin-Misener R, Clovis J, Rowe R, Beanlands $H$, et al. Interprofessional education for students of the health professions: the "Seamless Care" model. J Interprof Care. 2009; 23(3):224-33. 
19. Reeves S. Community-based interprofessional education for medical, nursing and dental students. Health Soc Care Commun. 2000; 8(4):269-76.

20. Freeth D, Hammick M, Reeves S, Koppel I, Barr H. Effective interprofessional education: development, delivery and evaluation. Oxford: Blackwell; 2005.

21. Friedson E. Professional dominance: the social structure of medical care. New York: Aldine Publishing Company; 1970.

22. Reeves S, MacMillan K, van Soeren M. Leadership within interprofessional health and social care teams: a socio-historical overview of some key trials and tribulations. J Nurs Manag. 2010; (18):258-64.

23. Pecukonis $E$, Doyle $O$, Bliss DL. Reducing barriers to interprofessional training: promoting interprofessional cultural competence. J Interprof Care. 2008; 22(4):417-28.

24. Rees $D$, Johnson R. All together now? Staff views and experiences of a pre-qualifying interprofessional curriculum. J Interprof Care. 2007; 21(5):543-55.

25. Leslie K, Baker L, Egan-Lee E, Esdaile M, Reeves S. Advancing faculty development in medical education: a systematic review. Acad Med. 2013; 88(7):1038-45.

26. Lindqvist S, Reeves S. Facilitators' perceptions of delivering interprofessional education: a qualitative study. Med Teacher. 2007; 29(4):403-5.

27. Wilhelmsson M, Pelling S, Ludvigsson J, Hammar M, Dahlgren LO, Faresjö T. Twenty years experience of interprofessional education in Linköping - ground-breaking and sustainable. J Interprof Care. 2009; 23(2):121-33.

28. Reeves S. Developing and delivering practice-based interprofessional education. Munich: VDM Publications; 2008.

29. Cooper H, Carisle C, Gibbs T, Watkins C. Developing an evidence base for interdisciplinary learning: a systematic review. J Adv Nurs. 2001; 35(2):228-37.

30. Hammick M, Freeth D, Koppel I, Reeves S, Barr H. A best evidence systematic review of interprofessional education. Med Teacher. 2007; 29(8):735-51.

31. Reeves S, Zwarenstein M, Goldman J, Barr H, Freeth D, Hammick M, et al. Interprofessional education: effects on professional practice and health care outcomes. Cochrane Database Syst Rev: CD002213; 2008.

32. Reeves S, Goldman J, Sawatzky-Girling B, Burton A. A synthesis of systematic reviews of interprofessional education. J Allied Health. 2010; 39 Supl 1:S198-S203. 
Reeves S. Porqué necesitamos la educación interprofesional para mejorar la prestación de una atención segura y eficaz. Interface (Botucatu). 2016; 20(56):185-96.

La educación interprofesional (IPE) es una actividad que implica dos o más profesiones que aprenden de manera interactiva, en conjunto, para mejorar la colaboración y la calidad del cuidado. La investigación ha revelado continuamente que los profesionales de salud y cuidado social encontran una gama de problemas con coordinación interprofesional y colaboración que afectan a la calidad y seguridad de la atención. Este trabajo empírico a resultado en políticas a través de la educación e y la prácica en salud para investir en IPE e ayudar a resolver estes fracasos de colaboración. IPE proporcionará profesionales de salud y atención social con las habilidades para trabajar juntos de manera efectiva para proporcionar atención segura de alta calidad a los pacientes. A través de una discusión de una gama de cuestiones profesionales, educativas y de organización relacionadas con $I P E$, este documento sostiene que este tipo de educación es una importante estrategia para mejorar la prestación de una atención segura y eficaz.

Palabras clave: Educación interprofesional. Aprendizaje colaborativo. Colaboración interprofesional. Trabajo en equipo. Seguridad del paciente.

Recebido em 06/02/15. Aprovado em 17/02/15. 